\title{
Editorial Letter 2015
}

\section{Dear Colleagues,}

the first issue of JPDP in 2015 gives a good opportunity to express our thanks to all, who are engaged and busy for our journal: Authors submitting their manuscripts, members of the Editorial Board for their continuous work on the quality of the papers and the reader of the papers.

During the year 2014 JPDP could affiliate three new members of the Editorial Board: Gerd Stammler, Limburgerhof, Germany, Alicia Cirujeda-Ranzenberger, Zaragoza, Spain and Paula Westerman, Rostock, Germany. With the end of 2014 unfortunately Theo Verwijst, Uppsala, Sweden declined his membership in the board. A late "welcome" to the three and many thanks to Theo for his contributions during the last years.

All other members of the Editorial Board are "on board" and will continue their assistance in 2015. Many thanks to all of you! JPDP receives an increasing number of manuscripts from all disciplines in crop protection and plant health - we heavily need the Editorial Board for selection and improvement in the review and publishing process.

In 2014 we were very pleased to start a series of reviews and are looking forward to continue this format. Please prepare and submit manuscripts with reviews articles.

Together with the Editorial Board we decided in 2014 trying to concentrate manuscripts in one issue around a topic. These topics can originate from a joint relation, a common problem or common methodologies. Joint projects may give good opportunities to fill one issue completely with manuscripts resulting from this project. To be clear: We do not produce Special Issues but normal ones with a thematic focus (topic issues). Thus, the manuscripts run through the normal review process and receive no special handling.

We are very pleased that the idea could be realized - in this first issue of 2015 you find contributions of a project consortium called KLIFF (Klimafolgenforschung Niedersachsen). Andreas von Tiedemann was engaged as additional Guest Editor for this first topic issue.

We kindly encourage our readership and potential authors to consider this opportunity if you have joint research projects, research networks or other initiatives resulting in contributions in the scope of JPDP. As paper handling runs in the normal process it is challenging to have 5-6 manuscripts coincidently ready for printing, but as you can see from this issue it worked! If you are interested in this opportunity please contact the Editorial Office as early as possible in the process. For sure topic issues will stay occasional in JPDP, mixed contribution of paper will continue to be the normal style.

For the up-coming issues of JPDP the Editorial Office is looking forward to your interesting, numerous and wellprepared submissions, original research papers, short communications and review papers!

Rostock, January 2015

Christine Struck

(Managing Editor)
Andreas von Tiedemann

(Guest Editor 1/2015)
Bärbel Gerowitt

(Editor-in-Chief) 